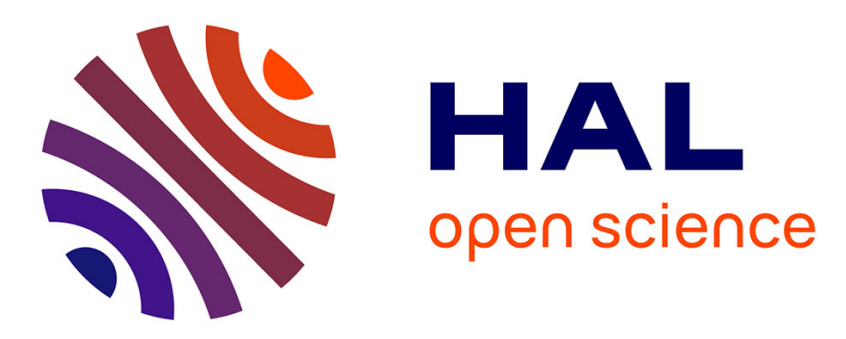

\title{
Atomic Supply Chain Modelling for Risk Management based on SCOR
}

Thibaut Cerabona, Matthieu Lauras, Jean-Philippe Gitto, Benoit Montreuil, Frederick Benaben

\section{- To cite this version:}

Thibaut Cerabona, Matthieu Lauras, Jean-Philippe Gitto, Benoit Montreuil, Frederick Benaben. Atomic Supply Chain Modelling for Risk Management based on SCOR. 22nd Working Conference on Virtual Enterprises (PRO-VE 2021), Nov 2021, Saint-Etienne, France. pp.601-610, 10.1007/9783-030-85969-5_56. emse-03346631

\section{HAL Id: emse-03346631 https://hal-emse.ccsd.cnrs.fr/emse-03346631}

Submitted on 25 Nov 2021

HAL is a multi-disciplinary open access archive for the deposit and dissemination of scientific research documents, whether they are published or not. The documents may come from teaching and research institutions in France or abroad, or from public or private research centers.
L'archive ouverte pluridisciplinaire HAL, est destinée au dépôt et à la diffusion de documents scientifiques de niveau recherche, publiés ou non, émanant des établissements d'enseignement et de recherche français ou étrangers, des laboratoires publics ou privés. 
Cerabona T., Lauras M., Gitto JP., Montreuil B., Benaben F. (2021) Atomic Supply Chain Modelling for Risk Management Based on SCOR. In: Camarinha-Matos L.M., Boucher X., Afsarmanesh H. (eds) Smart and Sustainable Collaborative Networks 4.0. PRO-VE 2021. IFIP Advances in Information and Communication Technology, vol 629. Springer, Cham. https://doi.org/10.1007/978-3-030-85969-5_56

\title{
Atomic Supply Chain Modelling for Risk Management based on SCOR
}

\author{
Thibaut Cerabona ${ }^{1}$, Matthieu Lauras ${ }^{1,2}$, \\ Jean-Philippe Gitto ${ }^{3}$, Benoit Montreuil², Frederick Benaben ${ }^{1,2}$, \\ ${ }^{1}$ Centre Génie Industriel, IMT Mines Albi, Campus Jarlard, \\ 81013 Albi CT Cedex 09, France \\ \{thibaut.cerabona, matthieu.lauras, frederick.benaben\}@mines-albi.fr
}

${ }^{2}$ ISyE, H Milton Steward School of Industrial \& Systems Engineering, 755 Ferst Drive GA 30332, Atlanta, USA

benoit.montreuil@isye.gatech.edu

${ }^{3}$ Scalian, 17 Avenue Didier Daurat, Batiment Pythagore, 31700 Blagnac, France

Jean-Philippe.GITTO@scalian.com

\begin{abstract}
At the time of instability becomes the norm (climate changes, natural disasters, epidemic, etc.) the management of collaborative networks, such as supply chains, is becoming more and more complex and critical. This instability only adds to the complexity of an already very complex system. Thus, supply chain managers have to adapt to multi-dimensional complex situations. Dealing with instability is a key expectation for these managers. One tool to help managers make decisions in this unstable environment is simulation. This article introduces some first results on an "atomic" reconfigurable supply chain simulation model based on Supply Chain Operations Reference (SCOR) model. This simulation tool will be used to apply an innovative physics-based approach of risk and opportunity management, that designs disturbances by forces moving the considered supply chain within its performance framework. This approach enables managers to monitor supply chain's performance trajectory by viewing and merging the impact of risks and opportunities.
\end{abstract}

Keywords: SCOR, supply chain management, risk management, performance measurement, physics and system modeling.

\section{Introduction}

At the times of climate changes, natural disasters and pandemics, instability becomes the norm. Supply chains as a very common collaborative network, do not escape and are strongly subjected to this instability. They operate in a dynamic, uncertain and risky environment. This instability increases the complexity of a system that is already very complex due to its network organization, which brings together various interdependent entities interconnected by the flow of money, goods and information. 
According to [1], the growth of supply chain complexity is accelerated by the following factors: globalization, sustainability, customization, outsourcing, innovation and flexibility. [2] identifies the eight most common sources generating this complexity: network, process, range, product, customer, supplier, organizational and information. Thus, supply chain managers have to analyze and adapt to more and more multi-dimensional complex situations. Dealing with instability is a key expectation for supply chain managers, whose purpose is to try to benefit from instability or at least, not to suffer from it. To be able to take advantage of this instability and manage such a complex system, managers need knowledge about the network organization and the business aspects of network operations [3]. But also, to identify and understand the causes of this instability and determine their consequences on all the activities of the supply chain [4]. Many tools and approaches exist to manage this complexity and help managers in their decision making. The solution chosen in this study is simulation. Indeed, according to [5], simulation is a favorable tool for the analysis and study of complex and dynamic systems such as supply chain networks. It allows decision makers to obtain accurate results [4]. However, the more complex the system is, the more difficult it is to model, and the more expensive it is in terms of time, resources and energy. According to [6], the development time of the simulation model represents about $45 \%$ of the total effort of a simulation project. The analysis and understanding of the cause and effect relationships of a disturbance and its impact on the performance of such a system become hard to obtain. Therefore, the use of standard reference models such as SCOR model (Supply Chain Operations Reference model) should make possible to create simulation models more quickly (especially for the conceptualization and modeling phases), by introducing understandable and standard processes and metrics [3].

The aim of this paper is to introduce our preliminary work on a modular reconfigurable supply chain model based on SCOR and its use as a decision support tool by serving as an input to a physics-based approach of risk and opportunity management, called Physics of Decision.

The remainder of the paper is organized as follows: section 2 presents the supply chain operations reference model. Section 3 introduces preliminary work on our "atomic" supply chain model and its application as decision support tool. The last section concludes on some perspective points, defining a roadmap to make this model and the innovative risk management approach presented functional.

\section{Supply Chain Operations Reference Model}

\subsection{SCOR Scope}

The SCOR model is a process reference model, that provides methodology, standard process definitions, metrics, diagnostic and benchmarking tools in order to improve supply chain processes and performance [7]. SCOR allows to link all these elements into a unique framework [7]. Since its introduction in 1996 by the Supply Chain Council, this model has been constantly reviewed and updated to consider all changes and developments in supply chain business practices. As mentioned in [8], SCOR is 
composed of three major parts. First, it is a modeling tool that uses and defines standard processes as building blocks for supply chain processes. By breaking down the processes of a supply chain into (re)/configurable process blocks [9], this model can be used to describe and model simple or very complex supply chains. This block breakdown gives a balanced horizontal (inter-process) and vertical (hierarchical) view compared to traditional process decomposition models [9]. The objective of this process structuration is to improve and support the understanding of all supply chain processes and best practices in order to improve the effectiveness of the supply chain management and its overall performance. Second, it defines a set of performance indicators called metrics. Third, it is a benchmarking tool that allows companies to compare with other companies, by comparing their performance indicators.

The two following sub-sections summarize the structure of the SCOR model based on information and materials from [7].

\subsection{SCOR Processes and Levels}

The SCOR model develops standard process divided into four hierarchical levels [3], as illustrated in Figure 1. Level 1 defines the six major and macro management processes: Source, Make, Deliver and Return for the goods and information flows, Enable for supply chain management activities and to support the others processes, and Plan to coordinate the five others processes [3]. Table 1 describes and defines these six major processes.

Table 1. Definitions of SCOR's Major Processes.

\begin{aligned} & \hline Major Process \multicolumn{1}{c}{ Definition } \\ & \hline Plan $\begin{array}{l}\text { balances the demand and supply of goods and resources in the } \\ \text { other processes in order to develop actions correlated to } \\ \text { business objectives [9]. } \\ \text { "contains processes that procure goods and services to meet } \\ \text { planned or actual demand" [9]. }\end{array} \\ &$\hline Make $\begin{array}{l}\text { describes the activities consisting of the transformation of raw } \\ \text { materials or products to a finished state. }\end{array} \\ &$\hline Deliver $\begin{array}{l}\text { consists of processes that provide finished products or } \\ \text { services to meet customer demand [9]. }\end{array} \\ &$\hline Return $\begin{array}{l}\text { deals with the activities associated with the reverse flow of } \\ \text { defective products [9]. }\end{array} \\ &$\hline Enable $\begin{array}{l}\text { describes all the activities associated with the supply chain } \\ \text { management [7]. Enable processes support the others } \\ \text { processes. }\end{array} \\ &$\hline\end{aligned}

These processes are decomposed into process categories in the level 2 depending on the type of business and strategies of the considered supply chain: make-to stock (MTS), make-to-order (MTO) and engineer-to-order (ETO). This level offers more details and simplifies the supply chain. For this level, SCOR model proposes a tool kit of 32 process categories. Thus, from this tool kit, each supply chain configuration can be modeled. Level 3 divides the identified processes of level 2 into generic and 
standard process elements. These process elements represent the steps of each process. Once these steps are assembled and performed in a certain order, they enable supply chain activities to be planned, materials to be sourced, products to be manufactured, goods and services to be delivered and product returns to be managed. Level 4 describes the detailed tasks for each of the level 3 activities. These tasks, and their interactions, are specific to each company. This level is not considered in our study, because it focuses on the process specific to each company.

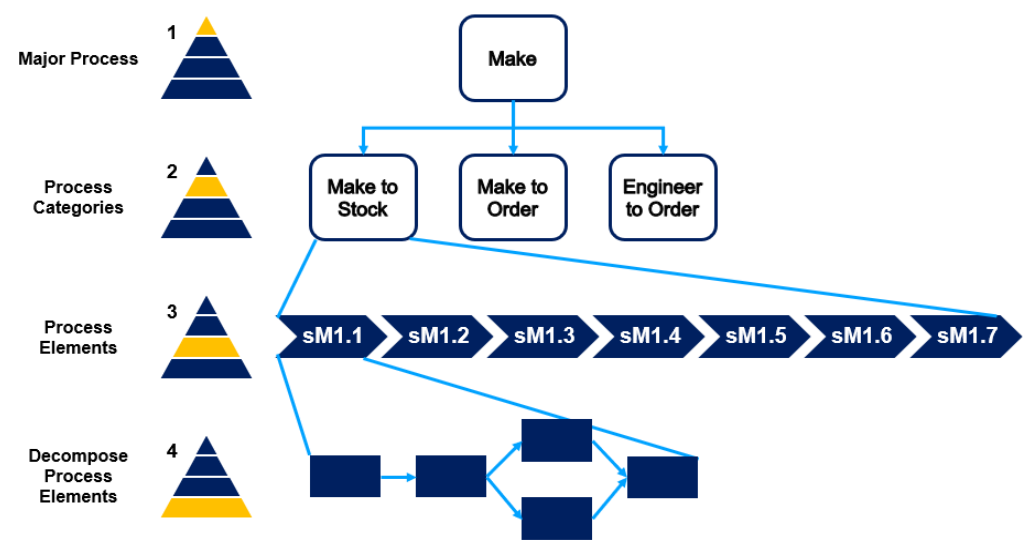

Fig. 1. SCOR process levels

\subsection{SCOR Metrics}

In order to evaluate and diagnose the performance of a supply chain, SCOR proposes an approach based on three elements: performance attributes, key performance indicators and best practices [7]. Performance attributes represent the strategic performance characteristics on which the performance of the considered supply chain must be aligned to be still with the business strategy. SCOR defines two types of performance attributes: customer and internal focused attributes. SCOR associates several key performance indicators, called metrics, with each of these performance attributes. These metrics are organized according to a hierarchical structure, i.e. at each level (level 1,2 or 3 ) a metric is associated to evaluate the process. This decomposition of the metrics allows an analysis of the supply chain performance according to root-causes. For example, the analysis of the performance of level 2 metrics can explain the gaps in performance of level 1 metrics. As mentioned in [8], each process is associated with a list of best practices to improve the metrics.

\section{Proposal: Atomic Reconfigurable Supply Chain Model}

\subsection{Background}

Currently, supply chain simulation is an integral part of discrete event simulation applications [10]. [11] mentions that the SCOR model can be used to build powerful 
simulation models based on discrete event simulation. In [11], the authors aim to create supply chain simulation models using the SCOR model, in order to facilitate the construction of these models and to create reusable components from a software allowing discrete event simulation. [12] proposes a comparison and evaluation of several modeling techniques. In this paper, the authors compare three simulation tools: Witness (a commercial simulation software), iGrafx Process (a process modelling and analysis tool) and e-SCOR (a supply chain simulator based on SCOR and developed by GenSym) through the modeling of the same use case. They concluded from their experiments that SCOR-based simulation tools offer advantages over other simulation tools. In particular, by using standard processes and performance indicators, these tools make it possible to build faster and easier to understand models (especially for people familiar with the SCOR model). The disadvantages of this kind of model are the lack of flexibility and the risk of simplifying and transforming certain strategies in order to fit the definitions of the SCOR model and thus modify the reality. In [13] another SCOR-based simulation model is introduced, IBM SmartSCOR that develops an integrated platform to support supply chain transformation by using several simulation and optimization techniques. [14] and [4] develop ontologies, that integrate different models based on SCOR framework and views using Integrated DEFinition (IDEF) suite. Supply chain ontology allows to capture the required knowledge about the supply chain. Their approach generates automatically supply chain models based on a set of predefined modules, derived from the level three of SCOR. [3, 8 and 10] offer SCOR Template model, that allows to model a supply chain by assembling bricks based on the level 2 or 3 of SCOR according to the versions and designed in Arena simulation software.

Based on all this work, it is clear that SCOR occupies an important place in the simulation of supply chains.

\subsection{Physics of Decision}

This atomic simulation model introduced in the next sub-section will be used to apply the Physics of Decision (POD) approach presented in [15]. Indeed, according to [11], simulation models are very interesting as a decision support and performance prediction tool. Simulation is an increasingly important methodological approach to theory development in the strategy and organization literature [16]. The POD approach is based on analogies with physical principles to support decision-making processes and help managers to navigate in unstable environment. To navigate in this kind of environment, managers need a tool that gives them access to information on the following three points, as mentioned in [17] and [15]: (1) the comprehension of the considered system and its environment, (2) understanding the possible consequences of different changes and (3) the mechanisms for selecting the different options available.

To answer the first point, POD approach develops two modelling spaces: the description space and the performance space. In a supply chain context, the description space is dedicated to the description of the considered supply chain and its environment. It represents the supply chain's location within its attribute dimensions (for instance customer demand, capacity, number of employees, etc.). It is 
illustrated in Figure 2. The value of its attributes changes as a result of the decisions taken by the managers. The degree of liberty for each attribute is set by the control space. It is a subspace in continuous change representing supply chain constraints and in which the supply chain is able to move freely (blue shape). The context characteristics represents a zone in this description space, where the supply chain is more susceptible to certain disruptions and potentials that may impact it (orange shape). There are four types of potentials:

- Environment: all potentials created by the system environment (e.g. new tax on imports of coarse metals from outside the European Union, etc.),

- Charges: mandatory system costs (e.g. wages, process times, etc.),

- Innovations: measures taken to improve the system (e.g. buy new machine, etc.),

- Interactions: represent all the potential generated by the relationships between the network's actors (e.g. customer request, flow of products, etc.).
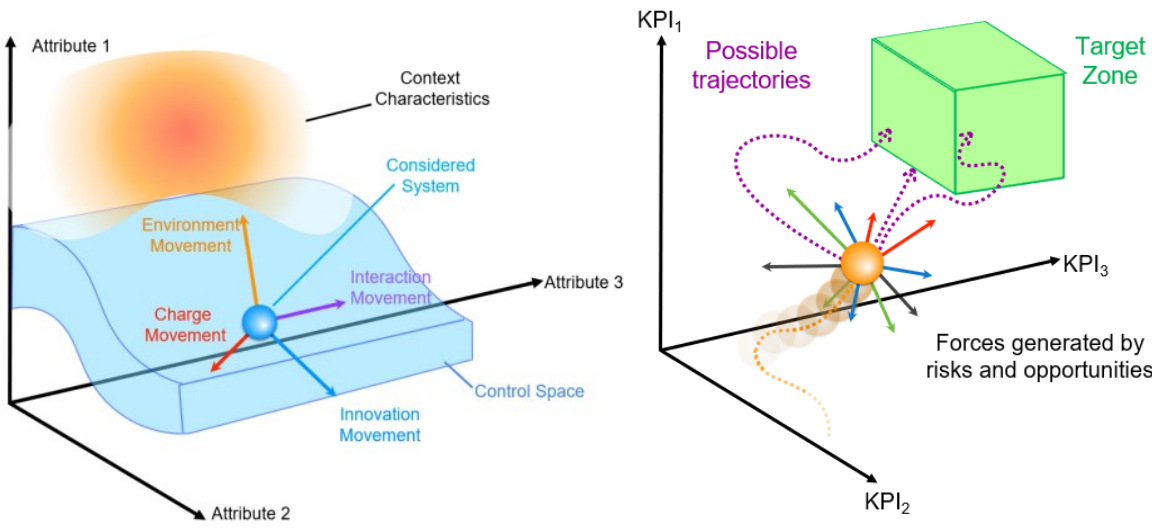

Fig. 2. Description (left) and Performance (right) Spaces

The performance space describes the performance of the supply chain. This performance space is illustrated in Figure 2. The first trajectory modeled in this framework is the inertia trajectory (dotted orange line). It represents the nominal performance trajectory of the observed system without any perturbation. It will serve as a reference in the analysis of the impact of risks and opportunities on the supply chain's performance. In this multi-dimensional key performance indicators (KPIs) framework, forces model and reflect the impact of risks and opportunities on the system (color vectors) [18]. Thus, the evolution of the supply chain's performance (schematically its position in the framework) is due to the achievement of risks or opportunities. As mentioned in [15], the main interest of the performance space is to obtain the performance trajectory of the supply chain, which is considered as a way to analyze the evolution of its performance over time. Moreover, as mentioned in [18], this framework is used as a decision support for managers, in particular by studying the best options to choose in order to reach the target area at lower "cost" (which will be modeled as a multi-objective function whose objective is to minimize the effort, i.e. at least the time and money, to reach this target subspace). Schematically, that 
means defining the best combination of forces to select in order to reach the target zone (the purple possible trajectories). The target zone is an area of the performance space designing the performance objectives of the considered supply chain (green parallelepiped). Its shape is still under study.

\subsection{Atomic Modelling Vision}

This POD approach allows to control and monitor the evolution of the global performance of the supply chain, by assessing the impact of macro risks and opportunities. However, with this approach, it is currently very difficult to evaluate and analyze the micro-consequences generated by the identified risks and opportunities. Especially, their impacts on certain actors or components of such a complex supply chain network. To resolve this problem, our idea is to develop a modular, "atomic", reconfigurable simulation model based on the SCOR model. This model is based on SCOR to take advantage of all the metrics, standard processes and meshes defined in this model. But also, to be able to develop a model accepted by the supply chain community, the only model widely accepted and shared by this community is the SCOR model (according to [14]). SCOR will also be used to define the level of decomposition of a supply chain network from which to build the atoms. Thus, atoms will be created from the 32 processes of level 2 of the SCOR model. In this first version of the model, only the Source, Make and Deliver processes for MTS and MTO products will be modeled. Thus, six atoms are necessary as summarized in Table 2. Each atom is a reconfigurable micro-model, modeling a main function of the supply chain. To be able to fulfill their duties, atoms will carry out actions corresponding to the steps and process elements defined in SCOR level 3. Figure 3 illustrates how the atoms are positioned in the SCOR framework.

Table 2. List of required atoms.

\begin{tabular}{c|c|c|c|c}
\hline Major Process & Atom & Atom Id & Inputs & Outputs \\
\hline \multirow{4}{*}{ Source } & MTS & S1 & $\begin{array}{c}\text { M1 } \\
\text { D1-Suppliers }\end{array}$ & M1 \\
\cline { 2 - 5 } & MTO & S2 & $\begin{array}{c}\text { M2 } \\
\text { D2-Suppliers }\end{array}$ & M2 \\
\hline \multirow{2}{*}{ Make } & MTS & M1 & S1 & D1 \\
\cline { 2 - 5 } & MTO & M2 & S2 & D2 \\
\hline \multirow{2}{*}{ Deliver } & MTS & D1 & M1 & S2-Customers \\
\cline { 2 - 5 } & MTO & D2 & M2 & \multicolumn{2}{c}{} \\
\hline
\end{tabular}

Each atom should be as configurable as possible, which means that each atom must be parametrizable and change its components (the value of its attributes) in order to adapt to the considered supply chain, its disturbances and decisions made by its managers. As mentioned in the previous subsection, this atomic model will be used to apply the POD approach. To do so, each atom will have its own description and performance spaces, in order to observe the micro-consequences of risks and opportunities on these atoms. In order to maintain a root-cause analysis of performance, the KPIs measured at the global supply chain level will be calculated 
using aggregation functions defined from the indicators measured at the atom level. Analogies with the properties of electrical voltage will be studied, for example if the network follows a "series connection" type structure, is the impact of the disturbance equal to the sum of the impacts of its micro-consequences.

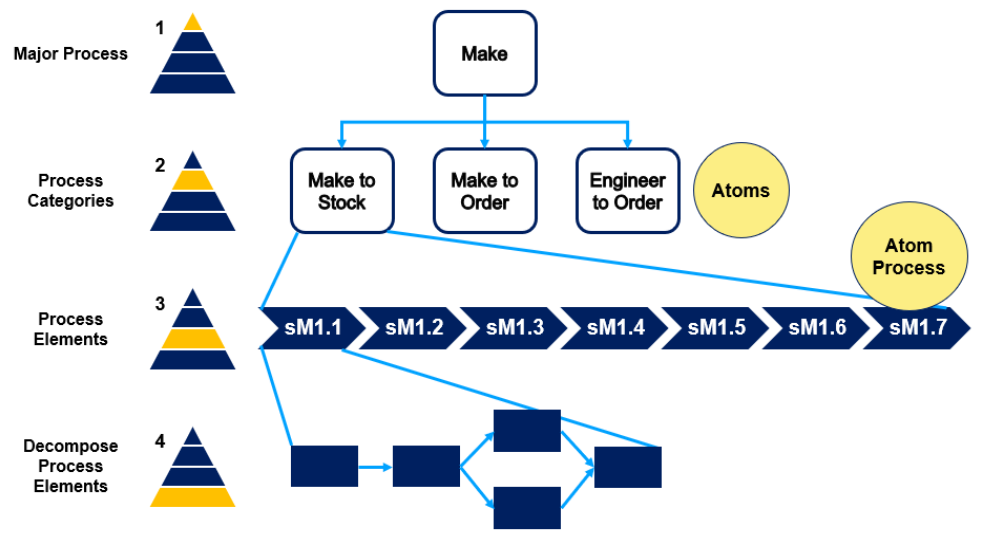

Fig. 3. Position of atoms in the SCOR framework

\subsection{A simple Illustrative Example}

Let's consider a simple example to illustrate this approach, taking the case of the supply chain of a company A. Company A produces plastic bottles and sells them to its only customer, Company B. To produce its bottles, A buys polyethylene terephthalate (PET) granulate from $\mathrm{C}$ and recycled PET flake from D. All these products follow a make to stock strategy. With this atomic approach, this supply chain will be modeled from the atoms of type: S1, M1 and D1. Each atom process will be modeled using Anylogic (C simulation software using the Process Modeling Library. Figure 4 gives an overview of the modeling of this supply chain with the approach presented in this article.

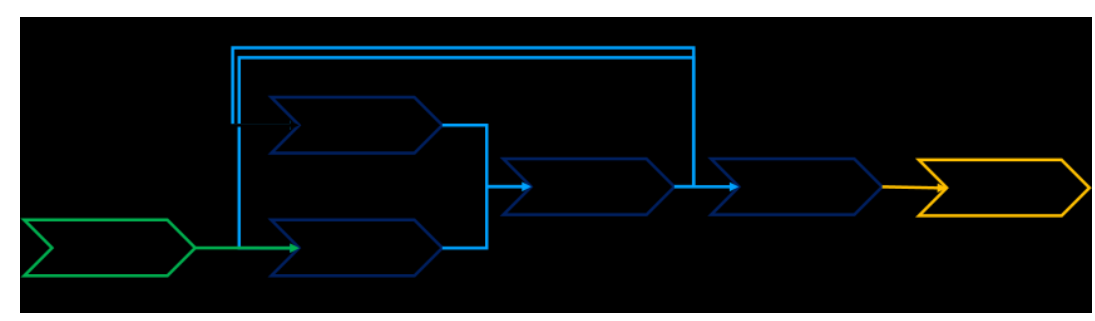

Fig. 4. Atomic model of this supply chain

This example illustrates how, starting from a simple case, it is possible to build brick by brick a supply chain and thus to model it, thanks to the atoms developed in this first version and their potential links (presented in Table 2). Once the block arrangement has been made, all these blocks must be parameterized according to the properties and values of the attributes of the studied supply chain. This example also 
illustrates the potential of this approach, particularly in the study of supply chain reconfiguration following the occurence of risks or opportunities. Studying different implementation of a supply chain, according to several configurations of building blocks allows to compare different obtained performance, resistance to disruption and resilience. The last step consists in implementing the set of performance indicators specific to each atom onto the simulation models of each of these atoms, and applying the POD approach presented in subsection 3.2. The objective of this approach is to provide an intuitive and immersive decision support tool, with which managers, following a "what if" reasoning, will be able to analyze the impact of disruptions but also micro-impacts on the key processes of their system. This tool can also be used to visualize and analyze the effectiveness of the corrective actions implemented.

\section{Conclusion and Perspectives}

This article introduces the first works carried out on this modular vision of the supply chain, the following perspectives define a roadmap to make that approach a functional practice. The first one consists in conducting simulation campaigns and sensitivity analyses to cover the widest range of values of the considered supply chain parameters and thus cover as much of the potential accessible description space as possible. The purpose of these simulations and analyses is to generate the volume of data necessary to study the sensitivity and fragility of the supply chain in the face of certain identified risks or opportunities, and thus define the associated forces. Then in a second step, these simulations and analyses aim to generate a sufficient amount of data to feed and train neural networks. They will forward replace atoms, as they offer a more reactive and even more scalable arrangement. Indeed, once trained correctly, neural networks will offer the possibility to study and predict the sensitivity and variability of the supply chain to a wide range of risks and opportunities. The second avenue concerns one of the key points to turn that model functional and suitable, the connectivity between atoms. The objective is to develop compatible bonds between atoms in order to allow them to interact with each other and to be able to build networks of atoms and so model supply chain networks. In particular, by taking inspiration from what has been achieved within the Physical Internet, particularly in the way it manages interfaces and interconnectivity of the developed logistics system.

\section{References}

1. Serdarasan, S.: A review of supply chain complexity drivers. Computers \& Industrial Engineering. 66, 3, 533-540 (2013). https://doi.org/10.1016/j.cie.2012.12.008.

2. Christopher, M.: Logistics \& Supply Chain Management. Financial Times Prentice Hall, Harlow (2011).

3. Persson, F.: SCOR template-A simulation based dynamic supply chain analysis tool. 7 (2011). 
4. Cope, D., Fayez, M., Mollaghasemi, M., Kaylani, A.: Supply chain simulation modeling made easy: An innovative approach. In: 2007 Winter Simulation Conference. pp. 18871896 IEEE, Washington, DC, USA (2007). https://doi.org/10.1109/WSC.2007.4419816.

5. Towill, D.R.: Supply chain dynamics. In: International Journal of Computer Integrated Manufacturing, vol. 4(4), pp. 197-208 (1991). https://doi.org/10.1080/09511929108944496

6. Mackulak, G. T., Lawrence, F. P.: Effective simulation model reuse: a case study for AMHS modeling. In: Proceedings of the 1998 Winter Simulation Conference. (1998).

7. Council, S.-C.: Supply-Chain Operations Reference-Model, Scor Version 12.0, SupplyChain Council (2017).

8. Persson, F., Araldi, M.: The development of a dynamic supply chain analysis toolIntegration of SCOR and discrete event simulation. International Journal of Production Economics. 121, 2, 574-583 (2009). https://doi.org/10.1016/j.ijpe.2006.12.064.

9. Huang, S.H., Sheoran, S.K., Keskar, H.: Computer-assisted supply chain configuration based on supply chain operations reference (SCOR) model. Computers \& Industrial Engineering. 48, 2, 377-394 (2005). https://doi.org/10.1016/j.cie.2005.01.001.

10.Persson, F., Bartoll, C., Ganovic, A., Lidberg, M., Nilsson, M. Wibaeus, J. Winge, F.: SUPPLY CHAIN DYNAMICS IN THE SCOR MODEL - A SIMULATION MODELING APPROACH. In Laroque, C., Himmelspach, J., Pasupathy, R. (eds.) Winter Simulation Conference Proceedings (2012).

11.Hermann, J.W., Lin, E., Pundoor, G.: Supply Chain Simulation Modeling Using the Supply Chain Operations Reference Model. In: Volume 1: 23rd Computers and Information in Engineering Conference, Parts A and B. pp. 461-469 ASMEDC, Chicago, Illinois, USA (2003). https://doi.org/10.1115/DETC2003/CIE-48220.

12.Albores, P., Love, D., Weaver, M., Stone, J., Benton, H.: An evaluation of SCOR modelling techniques and tools. In Proceedings of the EuroMot 2006 Conference. (2006).

13.Dong, J. et al.: IBM SmartSCOR - A SCOR Based Supply Chain Transformation Platform Through Simulation and Optimization Techniques. In: Proceedings of the 2006 Winter Simulation Conference. pp. 650-659 IEEE, Monterey, CA, USA (2006). https://doi.org/10.1109/WSC.2006.323142.

14.Fayez, M., Rabelo, L., Mollaghasemi, M.: Ontologies for Supply Chain Simulation Modeling. In: Proceedings of the Winter Simulation Conference, 2005. pp. 2364-2370 IEEE, Orlando, FL. USA (2005). https://doi.org/10.1109/WSC.2005.1574527.

15.Benaben, F., Faugere, L., Montreuil, B., Lauras, M., Moradkhani, N., Cerabona, T., Gou, J., $\mathrm{Mu}, \mathrm{W} .:$ Instability is the norm! A physics-based theory to navigate among risks and $\begin{array}{lllll}\text { opportunities. } & \text { Enterprise } & \text { Information } & \text { Systems. }\end{array}$ https://doi.org/10.1080/17517575.2021.1878391.

16.Davis, J. P., Eisenhardt, K. M., Bingham, C. B.: Developing theory through simulation methods. In: Academy of Management Review, vol. 32(2), pp. 480-499. (2007).

17.Simon, H.A.: A behavioral model of rational choice. In: Quarterly Journal of Economics, vol. 69(1), pp. 99-118 (1955)

18.Cerabona, T., Lauras, M., Faugère, L., Gitto, JP., Montreuil, B., Benaben., F.: A PhysicsBased Approach for Managing Supply Chain Risks and Opportunities Within Its Performance Framework. In: Camarinha-Matos, L.M. et al. (eds.) Boosting Collaborative Networks 4.0. pp. 418-427 Springer International Publishing, Cham (2020). https://doi.org/10.1007/978-3-030-62412-5 34. 